\title{
Time and Log Concentration Correlation
}

National Cancer Institute

\section{Source}

National Cancer Institute. Time and Log Concentration Correlation. NCI Thesaurus. Code C85821.

The correlation between time $(\mathrm{X})$ and log concentration $(\mathrm{Y})$ for the points used in the estimation of lambda z. 